\title{
The influence of climate change on the spread of human salmonellosis (Mini-review) ${ }^{\S}$
}

\section{Ekaterina SHMELEVA*}

Kaposvár University, Faculty of Agricultural and Environmental Science, H-7400 Kaposvár, Guba S. str. 40.

\begin{abstract}
Human salmonellosis is one of the most important food-borne diseases, which is caused by the serovars of Salmonella enterica. The mesophilic and hydrophilic bacteria, Salmonella serovars are expected to spread and cause an increased number of cases as a result of climate change. The interdependence of human salmonellosis and climate change is a complex phenomenon. Therefore, it needs a multidisciplinary method of analysis. Especially in low-income regions, both extreme weather events and diseases and their coexistence cause real disasters to the poorest communities. This review gathers the epidemiological and socioeconomic aspects of human salmonellosis to assess the main driving forces of infection. As a result, it was ascertained that the application of different disciplines helped to appreciate the important role of poverty in the epidemiology of human salmonellosis.
\end{abstract}

Keywords: salmonellosis; multidisciplinary; One Health; poverty

\section{INTRODUCTION}

Nowadays, food-borne diseases (FBDs) are increasing, and this process induces a growing public health problem causes a considerable socioeconomic impact all over the world. Every year, about 10 out of 100 people suffer from FBD, which frequently manifests in diarrheal diseases. These disorders often occur as a result of poor food storage and disruption of production processes on farms and slaughterhouses or meat factories. Usually, enteric pathogens (e.g. Salmonella serovars*) are the causative agents of diarrheal disorder, however in the case of Salmonella spp. the disease often asymptomatic (WHO, 2003).

The human population of the world is increasing rapidly. The activities of this expanding population contribute to global change through a very complex context (Zinsstag et al., 2018). Warming temperature causes heat waves, while the imbalance in the temporal distribution of precipitation leads to harsh summer droughts and heavy rainfalls with consequential floods (Stephen and Barnett, 2016). These extreme weather events contribute to the emergence and re-emergence of infectious diseases. Most of these health problems shared by humans, animals, and the environment (Essack, 2018; Zinsstag et al., 2018).

SIn this review the nomenclature system used by WHO was followed (Ryan et al., 2017).

*CORRESPONDING AUTHOR

Szent István University Kaposvár Campus

$\square$ H-7400 Kaposvár, Guba S. str. 40., 面 +36-82-505-800

E-mail:kafanni@yandex.ru 
The genus of Salmonella spp. is a typical example of a serious zoonotic threat for humans. The members of this genus, especially Salmonella enterica, cause food-borne diseases in both high-income and low-in come regions of the world (Garba et al., 2019; Thindwa et al., 2019). Since Salmonella species are mesophilic and hydrophilic bacteria, worldwide worsening of Salmonella situation is conceivable (Andino et al, 2015). Moreover, during extreme weather conditions, human and animal hosts are under stress, and floods can spread the pathogens extensively (Hallegatte and Rozenberg, 2017; Thindwa et al., 2019).

Being a food-safety concern, salmonellosis risk human well-being, especially in low-income countries, where it can deepen poverty. Losses caused by increased human healthcare costs, non-working days, damage to livestock contribute to the fiscal deficit and consequently decrease the sources, which can be invested in a safer food-chain. This vicious circle is named as "poverty trap" (Hanjra and Qureshi, 2010; Leichenko and Silva et al., 2014).

Salmonellosis and climate change have got a very complex interdependence. Moreover, the indirect consequence of this complicated phenomenon is even more complicated, with several socioeconomic and cultural aspects (Leichenko and Silva et al., 2014). Being a compound problem, climatic aspects of human salmonellosis need a multidisciplinary approach. One Health provides an effective way to analyses the whole issue of increasing Salmonella risk. The multidisciplinary approach to the risk analysis will result in complete appreciation of both biological and socio-economical sides of this serious health problem (Zinsstag et al., 2018).

This mini-review will outline the main interdependent factors of climate change and salmonellosis. By the methods of One Health approach, it attempts to demonstrate the usefulness of a multidisciplinary analysis of a very complex phenomenon, like human salmonellosis.

\section{GLOBAL CLIMATE CHANGE}

During the past 100 years, the global average surface temperature increased by $0.74{ }^{\circ} \mathrm{C}$ (Akil et al., 2014; Semenza and Menne, 2009), and a further temperature rise of $1.5-1.8{ }^{\circ} \mathrm{C}$ is predicted during the 21 st century (Xiaoxu et al., 2016). Nowadays, the rate of change in climate is faster than in any period in the last 100 years.

Warming temperature extends both the vegetation period and the reproduction seasons of potential vector species of infectious diseases within the temperate zone (Bronson, 2009; Hunter, 2003). Some vector species can become invaders in natural ecosystems. Climate change does not only support 
the reproduction of certain vector species but change their behaviour. Arthropods and rodents may find shelters in human premises against extreme weather events, which creates frequent interactions between vectors and humans (Semenza and Menne, 2009; Ribas et al., 2016; Wales et al., 2010). These conditions support the maintenance of even subtropical or tropical pathogens in the environment of human populations. The frequent movements of people augment this process. Travelling, transport and migration can spread different pathogens through continents (Semenza and Menne, 2009; Wales et al., 2010).

As a result of global climate change, the temporal distribution of precipitation shifts. Harsh summer droughts can be followed by heavy rainfall and consequential floods (Hallegatte and Rozenberg, 2017; Leichenko and Silva, 2014; Xiaoxu et al., 2016). During flood events, surface water can be contaminated with pathogens from poorly managed manure and wastewater. The contamination can enter the drinking water system, aquatic ecosystems and recreational waters, as well (Bondo et al., 2016; Stephen and Barnett, 2016). This phenomenon is especially characteristic for coastal communities, which are extremely vulnerable to bacterial or toxin contamination (Chengsheng et al., 2015).

The water crisis caused by long dry periods leads to the freshwater shortage of the most sensitive populations. It results in bad sanitation, low levels of food hygiene, overcrowding around water sources (Garba et al., 2019). All these conditions impair the ability of these communities to defend themselves against natural disasters, malnutrition and diseases. This vicious circle is the poverty trap, which captures $12 \%$ of the global inhabitants (Hubacek et al., 2017). Agricultural poverty leads to land abandonment and excessive urbanisation. Expanding high-density slums provide appropriate conditions for disease spread within the most fragile part of the settlements (Thindwa et al., 2019).

The health effect of global climate change is expected to be widespread geographically. Emergence and re-emergence of numerous infectious diseases are highly influenced by several environmental factors like changing climate (Mills et al., 2010), warming and weather extremes, such as droughts and flooding, predict changes in outbreaks being sensitive to climatic factors (McMichael et al., 2006).

The frequency of extreme temperature events is expected to grow during the upcoming decades. Therefore, public health professionals at a national and local level must take account of climatic data in the formulation of meaningful adaptation policy (Chengsheng et al., 2015). 
Climate changes can influence the pathogen emergence, which is linked with changes in microbial modification, epidemiological observation, human behaviour, demographics, globalisation, ecology and agriculture, and industry (Rose et al., 2001; Tauxe, 2002). Hydrology, weather and some geographical characteristics of the growing site may be the reason for the level and the frequency of transfer of pathogenic microorganisms from environmental sources. It should be taken into consideration that a combination of two or more specific factors stimulates the appearance of a pathogen (Hunter, 2003; Jaykus et al., 2008)

\section{SOME IMPORTANT FACTS ON HUMAN SALMONELLOSIS}

Salmonellosis is one of the most commonly reported gastrointestinal infections in the developing regions of the world (Chensheng et al., 2015; EFSA and $E C D C, 2019)$. Nearly 17 million people are concerned worldwide, with over 150,000 deaths annually. In low-income countries, the death rate reaches 10$20 \%$ of all infected persons (Garba et al., 2019; Thindwa et al., 2019).

Most of the Salmonella strains to cause human salmonellosis belongs to the species $S$. enterica. Seven subspecies and more than 2,600 serovars of this species are recognised. Over the past 120 to 160 million years of evolution, the serovars diverged widely in their ability to infect different mammals and birds (Winfield et al., 2004) therefore those are circulating through the whole ecosystem. It can be divided into three groups based upon their host range: hostadapted, host-restricted and broad-host-range or generalist serovars. Host-restricted Salmonella strains commonly cause systemic infections and are transmitted between host populations by apparently healthy carriers (Belay and Monroe, 2014; Silva et al., 2014). Generalist serovars are responsible for foodborne gastrointestinal diseases in humans (Andino et al., 2015; Silva et al., 2014).

The emergence of human-adapted pathogens among Salmonella serovars related to the Neolithisation process when the human community developed into an agricultural and pastoralist economy (Key et al., 2020). Most pathogens of salmonellosis are dangerous to humans resulting in a bacterial disease that affects the intestinal tract with serious consequences, such as diarrhoea containing mucus or blood. In advanced cases, gastrointestinal complications, cholecystitis, pancreatitis and hepatitis, immunosuppression can occur (Parry et al. 2002).

The dominance of $S$. Enteritidis serovar in human diseases is assumed to be the consequence of the successful elimination program in poultry flocks 
against $S$. Gallinarum and $S$. Pullorum. After the disappearance of the two poultry specific serovars, $S$. Enteritidis filled the vacant ecological niche following the rule of competitive exclusion (Silva et al., 2014; Winfield et al., 2004). The importance of ecological competition between serovars is also supported by the fact that where $S$. Enteritidis is endemic, it excludes $S$. Typhimurium from laying hen flocks (Wales et al., 2010).

In developed countries, salmonellosis is a food-borne zoonosis, which originates from industrialised food animal production. Among these conditions, the infection is often self-limiting; though it causes recognisable costs for the health care system and the patients' family (Sockett and Roberts, 1991). On the other hand, in Africa, humans provide a reservoir of Salmonella strains. Poor infrastructure and high poverty rates cause limited access to healthy water, especially during drought periods. In the rainy season, surface run-off during the heaviest rains causes contamination of water sources. Therefore, both drought and rains can be disadvantageous for a large population of immunologically susceptible individuals causing often fatal diseases (Garba et al., 2019; Thindwa et al., 2019).

The highest number of floods is recorded in Asian countries. Flooding occasions can result in the contamination of drinking water with bacterial pathogens, including Salmonella that may be originated from animal feeding operations, wastewater treatment plants, private septic systems (Semenza et al., 2012). Therefore, endemic regions for Salmonella outbreaks include developing countries in the Middle East, South Asia, South Central, many parts of Africa and Latin America (Tajkarimia et al., 2013).

Several climate-sensitive arthropod and vertebral species are a potential vector of salmonellosis. These hosts provide a safe environment for pathogens to survive for long periods outside the food-chain (Hilbert et al., 2012). As climate change alters the behavior of these populations, and some of them appear in the proximity of human settlements or even inside the houses, the risk of food-borne infections increases extremely. Sympatric rodents (Meerburg and Kijlstra, 2007; Ribas et al., 2016), flies (Blazar et al., 2011; Wales et al., 2010), cockroaches (Fathpour et al., 2003); darkling beetles (Hazeleger et al., 2008; Wales et al., 2010) and even phytophagous agricultural pests (Soto-Arias et al., 2014) can play a reservoir role in the epidemiological cycle of human salmonellosis.

The most favorable conditions of temperature for the growth of Salmonella spp. is $35-37^{\circ} \mathrm{C}$. There are several different sources of salmonella infection, including eggs, meat and other products (Andino et al., 2015; Pires et al., 2014). 
On extremely high-temperature days, the ecological condition provides a reasonable possibility to great bacterial amplification resulting in more cases of salmonellosis. Therefore, Salmonella infections proliferate during seasons characterised by increased temperature, which can boost the transmission and replication of bacteria to food crops, surface water and other possible sources of human infection (Grjibovski et al.,2014; Haley et al., 2009; Kovats et al., 2004; Lal et al., 2013; Micallef et al., 2012; Zhang et al., 2010).

Moreover, it is confirmed that at higher temperatures, Salmonella can spread more rapidly both on a food surface and in the animals' gut (McMichael et al., 2006). In the summer season, with a peak between July and September, the highest salmonella outbreaks can be observed. A significant positive correlation between each degree of temperature elevation and increase of the case numbers can also be recognised (Akil et al., 2014; Chensheng et al., 2015; McMichael et al., 2006; Xiaoxu et al., 2016).

In England and Wales, a delay is noticed between the commencement of the disease and high-temperature days. The spread of the disease reaches a peak at week one after the heatwave, but the new cases continue for five weeks. Similarly, in The Netherlands, the infection with $S$. Enteriditis evidence higher sensitivity to temperature compared to $S$. Typhimurium. Moreover, the infection with $S$. Typhimurium can be obtained through non-food contact and is more common in rural areas. These results suggest that temperature influences transmission of infection in about 35\% of all cases of salmonellosis in England and Wales, The Netherlands, Czech Republic, Spain, Switzerland, and Poland (Kovats et al., 2004).

On the other hand, extreme temperature days may affect the risk of Salmonella transmission due to some occasional pathways directly and indirectly, such as altering the bacterial proliferation and eating habits during hot days, respectively. Environmental temperature influences the development of Salmonella at various stages in the food chain, including bacterial loads on transport, improper storage and raw food production (Juneja et al., 2007; Kovats et al., 2004; Zhang et al., 2010).

Despite their connection to seasonal changes in temperature, Salmonella infections decline in Europe and the developed parts of the world in the last decades, because of great public health efforts (Zhang et al., 2010). On the other hand, the surveillance systems report less than $1 \%$ of food-borne outbreaks in developing countries (Tajkarimia et al., 2013), which is in contrast with the serious public health effect of salmonellosis (Hallegatte and Rozenberg, 2017; Garba et al., 2019; Thindwa et al., 2014). 


\section{SALMONELLOSIS IN LIVESTOCK}

At present, it is impossible to deny the fact that the climate is changing and there is global warming that affects livestock and the agricultural field. Climate change has a direct impact (high temperature) on the spread of infectious diseases among animals, the content of pathogenic substances in food, but also climate change indirectly affects (quantity and quality of harvest) the safety of farms. Changes in precipitation and the drier climate force farmers to implement various adaptation measures to climate change (changing harvest schedules, mixed livestock systems, use of drought-resistant feed).

Expect microbiological and chemical risks to reduce feed and food safety, which will affect changes in pathogen levels that depend on temperature changes. To improve adaptation measures and mitigate impacts, work should focus on more specific individualization of the impacts of climate scenarios (Bailey and Cosby, 2005).

In animal husbandry, the development of breeds less susceptible to high temperatures can serve as one of the effective ways to combat changes in climate conditions, but on the other hand, this method can provoke susceptibility to other pathogens (Tirado et al., 2010)

On particularly hot days, animals are moved inside to avoid stress, dehydration or heat stroke, which increases the transmission and spread of infection among the herd (WHO, 2017). Animals are the primary reservoir of Salmonella. Spreading into the environment has an outcome from human practices and animal behavior. Salmonella serovars are adapted to specific animal species: $S$. Gallinarum (poultry); $S$. Dublin (cattle); $S$. Choleraesuis (pigs), etc. (Acha and Szyfres, 2001).

In the sub-clinical form of the disease, animals may either have a latent infection or become a persistent carrier or temporary (Quinn et al., 2011).

In most types of food producing animals, Salmonella can be clinically not manifesting the disease for a long time. A reliable fact is that under stressful conditions (for example, ambiance high temperature), serovars that are not pathogenic can be the cause of the disease (EFSA, 2005b) Infected animals can secrete the bacterium Salmonella throughout their lives. Often diseased animals infect neighboring animals and serve to spread the infection throughout the farm, and the spread also occurs with the help of rats (Bögel. 1992).

Household and hygiene procedures have a huge impact to help animals resist the spread of Salmonella on the farm. Moving animals from one herd to 
another, you should pay attention to the quality of health of the new animals. Integration animals into new herds and the development of salmonellosis raising livestock without mixing animals from different herds is an effective health improvement measure. Cleaning and disinfection between batches are used in Salmonella control programs for broilers, pig farming, and beef production (EFSA, 2005a).

The method of disinfection includes emptying a pen of animals before the entrance of new animals to the herd. It is proved that violation of these procedures affects the spread of Salmonella, especially for poultry. Improving the biosecurity and hygiene system is a qualitative indicator of protection from Salmonella (Wierup et al., 1995)

Temperature changes can affect the efficiency of livestock products. For example, in the summer, the quality of products is expected to deteriorate, but warmer winters can bring a positive effect to the farm's economy, as energy costs will become less. Thus, the immunity of animals will not depend on changes in thermal factors during the year (Ferguson et al., 2018). The novelty and relevance of this problem remain completely unexplored, but measures to prevent the spread of infection should work ahead of time.

\section{Infection prevention in animal husbandry}

The collection of material shall be carried out either by isolating feces and determining viable bacteria in a sick animal or by post -mortem diagnosis. Methods of the determination of Salmonellosis: Culture methods(a traditional method), Detection of antibodies by enzyme immunoassay (EIA), Nucleic acidbased assays Real-time quantitative polymerase chain reaction using PCR ( $A n$ dino and Hanning, 2015).

If salmonellosis is detected in the flock, measures must be taken to minimize the spread of the disease such as: Isolation of infectious animals and treatment with antitoxin serum against salmonellosis. Clinically healthy and recovered animals are vaccinated after treatment or vaccinated during gestation period, allowing passive protection of the offspring for 6 weeks. Usually supportive therapy and good care are essential electrolyte correction, stabilization of the acid - base balance and parental or oral re-hydration are so important for health. Disinfection and cleaning of the space according to a schedule, feed contaminated is eliminated or decontaminated. The household is registered as safe after 30 days of the last case of the ill animals (EFSA, 2019).

The bodies of animals which have died of salmonellosis, and aborted fetuses must be utilize. The skin, wool and feathers of forcibly killed animals 
must be decontaminated. In all cases of compulsory slaughter of animals, organs and meat, bacteriological tests for salmonellosis must be carried out and, if the diagnosis is confirmed the meat is processed in accordance with the rules in force (Silva et al., 2014).

The procedure for the reception of products, transport, storage and sale of products in the 0commercial establishment is carried out in accordance with the hygiene regulation for the food trade.

\section{SALMONELLOSIS AND ITS TRANSMISSION}

Salmonellosis in humans can be transmitted through food consumed, such as eggs, milk, meat, and vegetables. Dairy products play an important role in the spread of these pathogens. Milk and milk products without pasteurization can be contaminated by different spices of Salmonella. Thus, the raw milk and products made from it can be the cause by spreading S. typhimurium (CDC, 2008).

It is supported by a Swiss outbreak in 2016-2017. In this case, the source of the infection was cheese which was made from unpasteurized milk. During the eradication it was revealed the problem was derived from $S$. Stanley contamination was discovered from Switzerland's cheese and affected above $94 \%$ of people (Pastore et al., 2008). Vegetables such as rucola, salads, tomatoes, seedbased food are consumed raw when the rules are violated of hygiene therefore it considers as a source of spread of Salmonella species. The common factors linked with vegetable contamination are cross-contamination, inappropriate storage and infected food handler (Toyofuku et al., 2006, Cahill et al., 2008).

Salmonella serotypes can be divided into host-specific (serotypes which can provoke the development of disease in one host species), host restricted (associated with one host species but can cause disease in other species), and generalist genotype (usually this is characterized by low mortality and gastrointestinal symptoms), which important for public and epidemiological health (Uzzau et al., 2000). Zoonotic diseases are transferred from animals to humans through many pathways (contaminated water or food and indirect or direct contact with animals). Animal contact is a major transmission of enteric pathogens approximately 60-70\% of occurring disease of zoonotic (Taylor et al., 2001). One of a common case it is cattle, when they are contaminated with different serovars in exhibitions, slaughterhouses at birth or post-birth, thus exposing workers to the risk of disease immediately. (Grimont and Weill, 2007). The swine industry has a variety of Salmonella contamination with high mortality. The bacteria are located in their feces for several days. All age groups are susceptible to bacterial infection but especially it is a big issue for 
weaned pigs because they do not have a strong immune system during this period. Nurseries or breeding herds are supported by a high impact of the epidemiological situation and environmental pollution and stress can play an important role in maintaining endemic infections (Cote et al., 2004). Poultry is one of the main reservoirs of Salmonella species. The prevalence of serovars in hatcheries is between 0-20 \% for chicken, 25-60\% for ducks, and about 30\% for geese (Bailey et al., 1994). This distribution may be developed in the future not only in commercial farms but in urban farming for backyard flocks. It is increase has the potential for growing animal contact transmission from livestock in urban and suburban settings (Bailey and Cosby, 2005).

Salmonella is one of the causes of hospitalization and death of people, who have or work with domestic or pet animals (veterinarians, farmers, and slaughterhouse employees). Every year the incidence of disease increases and to avoid an outbreak it is necessary to increase collaboration between veterinary service and health care professionals to inform about potential risks owners and workers about the causes of the spread of Salmonella and remind them of hygiene rules (Lejeune and Kersting, 2010). This is often the result of factors involving the ubiquitous distribution of Salmonella serovars, this is incorrect hygienic conditions of employees who work in a restaurant kitchen, incorrect cleaning of equipment in the food or feed industry $(C D C, 2008)$.

Animal feed that contains raw materials is contaminated by Salmonella species about $21 \%$. The dry feed contains less number of Salmonella but also, is one of the route human salmonellosis outbreak (Finley et al., 2008). Animal feed has an indirect and direct threat to animal and human health. However, adequate storage, cleaning contacts surface, and hygiene practices can help to reduce the direct risk of salmonellosis.

\section{METHODS OF ONE HEALTH APPROACH}

Around the Millennium, the emergence of highly pathogenic avian influenza (HPAI), severe acute respiratory syndrome (SARS), middle-east respiratory syndrome (MERS), and other infectious diseases originated from wildlife highlighted the need of a holistic approach that breaks down barriers between different medical disciplines. Analysing the background of these endemics, human-induced change of the environment proved to be the main drivers of these new zoonoses. Therefore, it became unambiguous that professions of one discipline cannot solve these complex health problems alone (Boqvist et al. 2018; Catry, 2017; Zinsstag et al. 2011, 2015). 
The central concept of One Health, demolition of interdisciplinary barriers, is not new. During the 19th century, Rudolf Virchow introduced the term "zoonosis" for diseases shared by humans and animals. In the middle of the $20^{\text {th }}$ century, an American veterinarian, Calvin W. Schwabe perceiving the link between human and animal health established the conception of One Medicine, which expressed a bilateral collaboration between the human and veterinary domains of medicine (Zinsstag et al. 2011, 2015).

The birth of One Health was a result of recognition that diseases are transmitted through the human-animal-environment interface, and the maintenance of epidemics depends on different factors of all three domains. Through attempts to solve complex health problems, epidemiologists faced plenty of issues with direct or indirect epidemiological relevance out of their narrow professions. Therefore, the professions of ecology, geography, climatology, sociology, economy, communication, management etc. are invited into multidisciplinary research groups to analyse the drivers of disease emergence (Allen-Scott et al. 2015; Frankson et al. 2016).

In a very complex epidemiological situation, all potential factors should be analysed. During this process, different fields of science will be involved to evaluate the potential role of a concerning factor in the maintenance or spread of disease.

\section{APPROACHING SALMONELLOSIS AND CLIMATE CHANGE BY ONE HEALTH}

Climate change and global warming promote the proliferation of several foods borne pathogens (Patz, 2008; WHO, 2020). Therefore, Salmonella infection is expected to increase in the future as climate change causes a further rise in the average ambient temperature (Bambrick et al., 2008). The health consequences of global climate change widely spread and correlates with preexisting social and economic disparities (Sheffield and Landrigan, 2011).

The tight interdependence of climate change and the epidemiology of human salmonellosis makes this health problem a typical One Health challenge. As it was demonstrated above, the connection between climate change and salmonellosis affects through a lot of different factors. Most of these can be analysed with the tools of epidemiology, but a detailed investigation reveals the serious socioeconomic background of human infection.

On the one hand, the expected increase of salmonellosis cases can be explained directly by the ecological demands of Salmonella bacteria. Warm and humid micro-environment will provide advantageous conditions for bacterial growth even out of the intestinal tract, which is the main niche of these bacte- 
ria (Akil et al., 2014; Andino et al., 2015; Stephen and Barnett, 2016). Notwithstanding, this phenomenon can be hardly influenced directly. On the other hand, global warming and its consequences have to be considered as an invariable or rather continually worsening factor, when health strategies are planned. All stakeholders of a defense program have to consider climate change.

Effective prevention strategies should be based on systematic surveillance. In the EU, member states continually monitor Salmonella levels in food-producing animals. Animal infection and human data are coordinated and analysed by the European Center for Disease Prevention and Control (ECDC) and the European Food Safety Agency (EFSA). All EU member states have agreed on tests and standards for determining salmonellosis. The trends in foodborne and zoonotic diseases are regularly communicated. The EU regulation standardises the methods of the surveillance program and outbreak management, which is mandatory for all member states (Hugas and Beloeil, 2014).

Effective surveillance programs should be rest on overall public awareness. The participation of veterinarians, human medical professionals, farmers, public health organisations, and even customers is essential in combating Salmonella. In low-income regions, the efficacy of the surveillance is decreased by the lack of public knowledge and the less effective communication line between stakeholders (Akil et al., 2014; Thindwa et al., 2014; Hallegatte and Rozenberg, 2017; Garba et al., 2019).

Another very important factor in prevention is impeding the spread of bacteria through the food chain. Prevention measures start at the base, ensuring higher quality and more hygienic animal feed. At the production stage, strict biosecurity measures, in addition to the application of vaccines and probiotics, should be the tools of a mitigation program (EFSA and ECDC, 2019).

The application of control measures needs comprehension of epidemiological connections. That is out of the question in the lack of basic knowledge. In Europe, the mitigation program is supported by an educational campaign (EFSA and ECDC, 2019). By contrast, in low-income countries, especially for the poorest communities, even basic education is hardly achievable. This situation is worsened by the limited access to clean water, sanitation infrastructure and appropriate sewage management. These extremely vulnerable communities of poor people are more often affected by environmental disasters than the higher income earners of the world. Floods, droughts, heat waves heavily impact them. Among these conditions, food-safety means the availability of food regardless of its quality or microbiological status (Hallegatte and Rozenberg, 2017). 
Though human salmonellosis is of a very important health concern in even the developed part of the world, the most serious health and socioeconomic consequences affect the poorest people. An effective prevention program is impeded predominantly by the shortage of financial resources. In deep poverty, people cannot investigate into hygiene and education, which are essential for wholesome food production. Without the fulfillment of daily food needs, severe malnutrition and significant immunological imbalance make people susceptible to any infectious diseases. Loss of health is an expensive statement accompanying medical costs and non-working days. These costs decrease the income of the families, thus the input into preventive efforts. This poverty trap evolves a vicious circle from which the escape is almost impossible (Hanjra and Qureshi, 2010; Leichenko and Silva, 2014).

\section{CONCLUSION}

Summarising the facts of the reviewed works, it is obvious that human salmonellosis is more than a simple epidemiological problem of human patients. The climate change can be recognised as a disadvantageous invariable of the environment, which the humans must live with. Among these conditions, both direct and indirect effects of climate change on salmonellosis must be regarded. The ecological demands of Salmonella bacteria explain the simplest connection between salmonellosis and climate change. Notwithstanding, the interdependence is more complex. In the temperate zone, despite previous successful mitigation programs, an increase in cases is expected. Prolonged warm-season results in longer environmental survival of bacteria, dependence on refrigeration systems, extended reproduction season of potential vector species and altered eating habits of people (Silva et al., 2014; Andino et al., 2015; EFSA and $E C D C, 2019$ ).

Of the sorted consequences of climate change, the ecology of vectors and eating habits are not classical issues of epidemiology. To assess the exact risk of a grill-party with medium roasted steak, raw vegetables and a group of people needs interdependent cooperation of gastronomy professionals, microbiologists, plant health care managers, sociologists, human and veterinary doctors. If this event is held in a forested area, the working group should be augmented with ecologists with the knowledge on vector species of food-borne diseases (Essack, 2018; Silva et al., 2014; Zinsstag et al. 2018).

In the tropical zone, especially within the low-income regions, the impacts of climate change are more disastrous. Heatwaves and floods are responsible not only for bacterial survival and food spoilage but causes serious damage to poor people. Their properties, health and life, can be destroyed by even one 
extreme weather event (Hallegatte and Rozenberg, 2017; Hubacek et al., 2017). Among these circumstances, salmonellosis is rather an indicator of bad hygiene, limited access to water and sanitation, and low education than a simple health problem. The health effects of the poverty trap need a more complex approach. A group of economists and sociologists with expertise in poverty augmented with both human and veterinary medical professionals will be able to analyse the epidemiological situation of human salmonellosis in poor communities (Garba et al., 2019; Hallegatte and Rozenberg, 2017; Thindwa et al., 2019).

In low-income countries, the root of health problems is poverty. Climate change, extreme weather and diseases are factors that deepen its rate. It is the reason why the health problems of poor people cannot be solved by solely the health service. Combat against emerging infectious diseases of the poor is a real One Health challenge for the whole humans (Hanjra and Qureshi, 2010; Hubacek et al., 2017).

The environmental reservoir of salmonellosis is expanding both in spatial and temporal scales due to the changing climatic effect (Moser et al., 2012). The most severe, often fatal salmonellosis cases occur within the poorest communities of the world. For this reason, multidisciplinary efforts are needed against poverty to implement large-scale management of human salmonellosis.

\section{REFERENCES}

Akil, L., Ahmad, H.A., \& Reddy, R. S. (2014). Effects of climate change on Salmonella infections. Foodborne Path. Disease. 11, 974-980. DOI: $\underline{10.1089 / f p d .2014 .1802}$

Allen-Scott, L.K., Buntain, B., Hatfield, J.M, Meisser, A., \& Thomas, C.S. (2015). Academic institutions and One Health: Building capacity for transdisciplinary research approaches to address complex health issues at the animal-human-ecosystem interface. Acad. Med., 90, 866-871. DOI: 10.1097/ACM.0000000000000639

Andino, A., \& Hanning I. (2015). Salmonella enterica: Survival, colonisation, and virulence differences among serovars. Sci. World J. 520179, 1-16. DOI: $\underline{10.1155 / 2015 / 520179}$

Acha, P.N., \& Szyfres, B. (2001). Zoonoses and communicable diseases common to man and animals, 3rd Ed. Pan American Health Organization, Scientific Publication No. 580, Washington D.C.

Bambrick, H., Dear, K., Woodruff, R., Hanigan, I., \& McMichael, A. (2008). The impact of climate change on three health outcomes: Temperature-related mortality and hospitalisations, salmonellosis and other bacterial gastroenteritis, and the population at risk from dengue. Garnaut Climate Change Rev.

Bailey, J.S., Cox, N.A., \& Berrang, M.E. (1994). Hatchery-acquired Salmonellae in broiler chicks. Poult. Sci. 73(7), 1153-1157. DOI: 10.3382/ps.0731153

Bailey, J.S., \& Cosby, D.E. (2005). Salmonella prevalence in free-range and certified organic chickens. J. Food. Prot. 68(11), 2451-2453. DOI: 10.4315/0362-028X-68.11.2451

Belay, E.D, \& Monroe, S.S. (2014). Low-incidence, high-consequence pathogens. Emerg. Infect. Dis. 20, 319-21. DOI: $10.3201 /$ eid2002.131748 
Blazar, J., Allard, M., \& Lienau, E.K. (2011). Insects as vectors of food-borne pathogenic bacteria. Terrestr. Arthropod. Rev. 4, 5-16. DOI: 10.1163/187498311X543989

Bögel K. (1992). Global cooperation in the control of salmonellosis. In: Snoyenbos GH, editor. Proceedings of the Symposium on the Diagnosis and Control of Salmonella, 29 October 1991. San Diego: United States Animal Health Association; Library of Congress Catalog card Number 17-128242; 1992. p. 1-6.

Boqvist, S., Söderqvist, K., \& Vågsholm, I. (2018). Food safety challenges and One Health within Europe. Acta. Vet. Scand. 60:1. DOI: 10.1186/s13028-017-0355-3

Bondo, K.J., Pearl, D.L., Janecko, N. et al. (2016). Impact of season, demographic and environmental factors on Salmonella occurrence in raccoons (Procyon lotor) from swine farms and conservation areas in southern Ontario. PloS One, 11(9), e0161497. DOI: 10.1371/journal.pone.0161497

Bronson, F. H. (2009). Climate change and seasonal reproduction in mammals. Phil. Trans. Royal. Soc. B. Biol. Sci. 364, 3331-3340. DOI: 10.1098/rstb.2009.0140

Catry, B. (2017). Antimicrobial policies in animals and human health. Arch. Publ. Health. 75, 62. DOI: 10.1186/s13690-017-0231-7

Cahill, S.M., Wachsmuth, I.K., Costarrica, M.L., \& Ben Embarek, P.K. (2008). Powdered infant formula as a source of infection in Salmonella infants. Clin. Infect. Dis. 46(2), 268-273. DOI: 10.1086/524737

CDC, Centers for Diseases Control and Prevention (2008). Multistate outbreak of Salmonella infections associated with frozen pot pies United States, 2007. Morb. Mortal. Wkly. Rep. 57(47), 1277-1280.

Chengsheng, J., Shaw, K.S, Upperman, C.R., Blythe, D., Clifford, M., Sapkote, A.R., \& Sapkota, A. (2015). Climate change, extreme events and increased risk of salmonellosis in Maryland, USA: Evidence for coastal vulnerability. Environt. Int. 83, 58-62. DOI: 10.1016/j.envint.2015.06.006

Cote, S., Letellier, A., Lessard, L., \& Quessy, S. (2004). Distribution of Salmonella in tissues following natural and experimental infection in pigs. Can. J. Vet. Res. 68(4), 241-248.

EFSA (European Food Safety Authority) (2005a). Opinion of the scientific panel on animal health and welfare on a request from the Commission related to welfare of weaners and rearing pigs: effects of different space allowances and floor types. EFSA J. 3(10), 268. DOI: 10.2903/j.efsa.2005.268

EFSA (European Food Safety Authority) (2005b). Trends and sources of zoonoses, zoonotic agents and antimicrobial resistance in the European Union in 2004. EFSA J., 3(12), 310. DOI: $\underline{10.2903 / j . e f s a .2005 .310 a r}$

EFSA (European Food Safety Authority) and ECDC (European Centre for Disease Prevention and Control) (2019). The European Union One Health 2018 Zoonoses Report. EFSA J., 17, 5926. DOI: $\underline{10.2903 / j . e f s a .2019 .5926}$

Essack, S. Y. (2018). Environment: the neglected component of the one health triad. Lancet Planet Health. 2, 238-239. DOI: 10.1016/S2542-5196(18)30124-4

Fathpour, H., Emtiazi, G., \& Ghasemi, E. (2003). Cockroaches as reservoirs and vectors of drug resistant Salmonella spp. Iranian. Biomed. J. 7, 35-38.

Ferguson, L.V., Kortet, R., \& Sinclair, B.J. (2018). Eco-immunology in the cold: the role of immunity in shaping the overwintering survival of ectotherms. J. Exp. Biol. 221(13), jeb163873. DOI: $\underline{10.1242 / j e b .163873}$

Finley, R., Reid-Smith, R., Ribble, C., Popa, M., Vandermeer, M., \& Aramini, J. (2008). The occurrence and antimicrobial susceptibility of salmonellae isolated from commercially available canine raw food diets in three Canadian cities. Zoonoses Publ. Health. 55(8-10), 462-469. DOI: 10.1111/j.18632378.2008.01147.x

Frankson, R., Hueston, W., Christian, K., Olson, D., Lee, M., Valeri, L., Hyatt, R., Annelli, J., \& Rubin, C. (2016). One Health core competency domains. Front. Publ. Health. 4, 192. DOI: $\underline{10.3389 / \text { fpubh.2016.00192 }}$ 
Garba, B., Saidu, B., \& Mahmuda, A. (2019). Current trend on the economic and public health significance of salmonellosis in Iraq. Adv. Anim. Vet. Sci. 7, 484-491. DOI: 10.17582/journal.aavs/2019/7.6.484.491

Grjibovski, A.M, Kosbayeva, A, \& Menne, B. (2014). The effect of ambient air temperature and precipitation on monthly counts of salmonellosis in four regions of Kazakhstan, Central Asia in 2000-210. Epidemiol. Infect. 142, 608-615. DOI: 10.1017/S095026881300157X

Grimont, P.A.D., \& Weill, F-X. (2007). Antigenic formulae of the Salmonella serovars. 9th ed. Paris, WHO Collaborating Center for Reference and Research on Salmonella.

Haley, B.J, Cole, D.J, \& Lipp, E.K. (2009). Distribution, diversity, and seasonally of waterborne Salmonellae in a rural watershed. Appl. Environ. Microbiol. 75, 1248-1255. DOI: 10.1128/AEM.01648-08

Hallegatte, S., \& Rozenberg, J. (2017). Climate change through a poverty lens. Nature. Clim. Change. 7, 250-256. DOI: 10.1038/nclimate3253

Hanjra, M.A., \& Qureshi, M.E. (2010). Global water crisis and future food security in an era of climate change. Food. Policy. 35, 365-377. DOI: 10.1016/j.foodpol.2010.05.006

Hazeleger, W.C., Bolder, N.M., Beumer, R.R., \& Jacobs-Reitsma, W.F. (2008). Darkling beetles (Alphitobius diaperinus) and their larvae as potential vectors for the transfer of Campylobacter jejuni and Salmonella enterica serovar paratyphi B variant Java between successive broiler flocks. Appl. Environ. Microbiol. 74, 6887-6891. DOI: 10.1128/AEM.00451-08

Hilbert, F., Smulders, F. J. M., Chopra-Dewasthaly, R., \& Paulsen, P. (2012). Salmonella in the wildlifehuman interface. Food. Res. Internat. 45, 603-608. DOI: 10.1016/j.foodres.2011.08.015

Hubacek, K., Baiocchi, G., Feng, K. \& Patwardhan, A. (2017). Poverty eradication in a carbon constrained world. Nat. Commun. 8, 912. DOI: 10.1038/s41467-017-00919-4

Hugas, M., \& Beloeil, P. (2014). Controlling Salmonella along the food chain in the European Union progress over the last ten years. Euro. Surveill.19, 20804. D0I: $\underline{10.2807 / 1560-}$ 7917.ES2014.19.19.20804

Hunter, P.R. (2003). Climate change and waterborne and vector - borne disease. J. Appl. Microbiol. 94, 37-46. DOI: 10.1046/j.1365-2672.94.s1.5.X

Jaykus, L.A, Woolridge, M., Frank, J.M., Miraglia, M., McQuatters-Gollop, A., Tirado, C., Clarke, R., \& Friel, M. (2008). Climate change: Implications for food safety. FAO, Rome, pp. 45-49.

Juneja, V.K., Valenzuela Melendres, M., Huang, L., Gumudavelli, V., Subbiah, J., \& Thippareddi, H. (2007) Modeling the effect of temperature on growth of Salmonella in chicken. Food. Microbiol. 24, 328335. DOI: $10.1016 /$ i.fm.2006.08.004

Key, F.M., Posth, C., Esquivel-Gomez, L.R., Hüblern R., Spyrou, M.A., Neumann, G.U., Furtwängler, A., Sabin, S., Burri, M., Wissgott, A., Lankapalli, A.K., Vågene, Å.J., Meyer, M., Nagel, S., Tukhbatova, R., Khokhlov, A., Chizhevsky, A., Hansen, S., Belinsky, A.B., Kalmykov, A., Kantorovich, A.R., Maslov, V.E., Stockhammer, P.W., Vai, S., Zavattaro, M., Riga, A., Caramelli, D., Skeates, R., Beckett, J., Gradoli, M.G., Steuri, N., Hafner, A., Ramstein, M., Siebke, I., Lösch, S., Erdal, Y.S., Alikhan, N.F., Zhou, Z., Achtman, M., Bos, K., Reinhold, S., Haak, W., Kühnert, D., Herbig, A., \& Krause, J. (2020). Emergence of humanadapted Salmonella enterica is linked to the Neolithization process. Nat. Ecol. Evol. 4, 324-333. DOI: $\underline{10.1038 / s 41559-020-1106-9}$

Kovats, R.S., Edwards, S.J., Hajat, S., Armstrong, B.G., Ebi, K.L, \& Menne, B. (2004). The effect of temperature on food poisoning: a time-series analysis of salmonellosis in ten European countries. Epidemiol. Infect. 132, 443-453. DOI: 10.1017/S0950268804001992

Lal, A., Ikeda, T., French, N., Baker, M.G., \& Hales, S. (2013). Climate variability, weather and enteric disease incidence in New Zealand: time series analysis. PLoS One. 8(12), e83484. DOI: 10.1371/journal.pone.0083484

Leichenko, R., \& Silva, J.A. (2014). Climate change and poverty: vulnerability, impacts, and alleviation strategies. WIREs. Climate. Change. 5, 539-556. DOI: 10.1002/wcc.287 
Lejeune, J., \& Kersting, A. (2010). Zoonoses: an occupational hazard for livestock workers and a public health concern for rural communities. J. Agric. Saf. Health. 16, 161-79. DOI: $10.13031 / 2013.32041$

McMichael, A.J., Woodruff, R.E, \& Hales S. (2006). Climate change and human health: Present and future risks. Lancet. 367, 859-869. DOI: 10.1016/S0140-6736(06)68079-3

Micallef, S. A., Goldstein, R. E., George, A., Kleinfelter, L., Boyer, M.S., McLaughlin, C.R., Estrin, A., Ewing, L., Jean-Gilles Beaubrun, J., Hanes, D.E., Kothary, M.H., Tall, B.D., Razeq, J.H., Joseph, S.W., \& Sapkota, A.R. (2012). Occurrence and antibiotic resistance of multiple Salmonella serotypes recovered from water, sediment and soil on mid- Atlantic tomato farms. Environ. Res. 114, 31-39. DOI: $\underline{10.1016 / j . e n v r e s .2012 .02 .005}$

Meerburg, B.G., \& Kijlstra, A. (2007). Role of rodents in transmission of Salmonella and Campylobacter. J. Sci. Food. Agric. 87(15), 2774-2781. DOI: 10.1002/jsfa.3004

Mills, J.N, Gage, K.L, \& Khan, A.S. (2010). Potential influence of climate change on vector-borne and zoonotic disease: A review and proposed research plan. Environ. Health. Perspect. 118, 1507-1514. DOI: $10.1289 /$ ehp.0901389

Moser, S.C, Jeffress, W.S, \& Boesch, D.F. (2012). Wicked challenge at land's end: managing coastal vulnerability under climate change. Annu. Rev. Environ. Resour. 37, 51-78. DOI: 10.1146/annurev-environ-021611-135158

Parry, C., Hien, T.T., Dougan, G., White, N., \& Farrar, J. (2002). Typhoid fever. N. Engl. J. Med. 347(22), 1770-1782. DOI: $10.1056 /$ NEJMra020201

Pastore, R., Schmid, H., Altpeter, E., Baumgartner, A., Hächler, H., Imhof, R., Sudre, P., \& Boubaker, K. (2008). Outbreak of Salmonella serovar Stanley infections in Switzerland linked to locally produced soft cheese, September 2006 - February 2007. Euro Surveill. 13(37), 18979. DOI: 10.2807/ese.13.37.18979-en

Patz, J.A, Olson, S.H, Uejio, C.K, \& Gibbs, H.K. (2008). Disease emergence from global climate and landuse change. Med. Clin. North. Am. 92, 1473-1491. DOI: 10.1016/j.mcna.2008.07.007

Pires, S.M., Vieira, A.R., Hald, T., \& Cole, D. (2014). Source attribution of human salmonellosis: an overview of methods and estimates. Food-borne. Pathog. Dis. 11, 667-676. DOI: 10.1089/fpd.2014.1744

Quinn, P.J., Markey, B.K., Carter, M.E., Donnelly, W.J.C., \& Leonard F.C. (2011). Veterinary microbiology and microbial disease, 2nd ed. Wiley-Blackwell, Oxford.

Ribas, A., Saijuntha, W., Agatsuma, T., Prantlová, V., \& Poonlaphdecha, S. (2016). Rodents as a source of Salmonella contamination in wet markets in Thailand. Vector. Borne. Zoonotic. Dis. 16(8), 537-540. DOI: $10.1089 / v b z .2015 .1894$

Rose, J.B., Epstein, P.R., Lipp, E.K., Sherman, B.H., Bernard, S.M., \& Patz, J.A. (2001). Climate variability and change in the United States: Potential impacts on water and foodborne diseases caused by microbiologic agents. Environ. Health Perspect.109 (Suppl 2), 211-221. DOI: $\underline{10.1289 / e h p .01109 s 2211}$

Ryan, M.P., O'Dwyer, J., \& Adley, C.C. (2017). Evaluation of the complex nomenclature of the clinically and veterinary significant pathogen Salmonella. BioMed. Res. Int. 2017:3782182. DOI: 10.1155/2017/3782182

Semenza, J.C., \& Menne, B. (2009). Climate change and infectious diseases in Europe. Lancet Infect. Dis. 9(6), 365-375. DOI: 10.1016/S1473-3099(09)70104-5

Semenza, J.C., Herbst, S., Rechenburg, A., Suck, J.E., Hoser, C., Schreiber, C., \& Kistemann, T. (2012). Climate change impact assessment of food - and waterborne diseases. Crit. Rev. Environ. Sci. Technol. 42, 857-890. DOI: $\underline{10.1080 / 10643389.2010 .534706}$ 
Sheffield, P.E, \& Landrigan, P.J. (2011). Global climate change and children's health: Threats and strategies for prevention. Environ. Health. Perspect. 119, 291-298. DOI: 10.1289/ehp.1002233

Silva, C., Calva, E., \& Maloy, S. (2014). One Health and food-borne disease: Salmonella transmission between humans, animals, and plants. Microbiology. Spectr. 2(1), OH-0020-2013. DOI: $\underline{10.1128 / 9781555818432 . c h 9}$

Sockett, P.N., \& Roberts, J.A. (1991). The social and economic impact of salmonellosis. A report of a national survey in England and Wales of laboratory-confirmed Salmonella infections. Epidem. Infect. 107(2), 335-347. DOI: 10.1017/S0950268800048974

Soto-Arias, J. P., Groves, R. L., \& Barak, J. D. (2014). Transmission and retention of Salmonella enterica by phytophagous hemipteran insects. Appl. Environ. Microbiol. 80(17), 5447-5456. DOI: $\underline{10.1128 / A E M .01444-14}$

Stephen, D.M., \& Barnett, A.G. (2016). Effect of temperature and precipitation on salmonellosis cases in South-East Queensland, Australia: an observational study. BMJ Open. 6(2), e010204. DOI: 10.1136/bmjopen-2015-010204

Tauxe, R.V. (2002). Emerging foodborne pathogens. Int. J. Food. Microbiol. 78, 31-41. DOI: $\underline{10.1016 / S 0168-1605(02) 00232-5}$

Taylor, L.H., Latham, S.M., \& Woolhouse, M.E. (2001). Risk factors for human disease emergence. Phil. Trans. R. Soc. Lond. 356, 983-989. DOI: 10.1098/rstb.2001.0888

Tajkarimia, M., Ibrahim, S.A., \& Frasers, A.M. (2013). Food safety challenges associated with traditional foods in Arabic speaking countries of the Middle East. Trends. Food. Sci. Technol. 29, 116-123. DOI: $\underline{10.1016 / j . t i f s .2012 .10 .002}$

Tirado, M.C., Clarke, R., Jaykus, L.A., McQuatters-Gollop, A., \& Frank, J.M. (2010). Climate change and food safety: A review. Food Res. Int. 43, 1745-1765. DOI: 10.1016/j.foodres.2010.07.003

Toyofuku, H., Kubota, K., \& Morikawa, K. (2006). Outbreaks of Salmonella in infants associated with powdered infant formula. Bullet. Nat. Inst.Health Sci. 124, 74-79.

Thindwa, D., Chipeta, M.G., Henrion, M.Y.R., \& Gordon, M.A. (2019). Distinct climate influences on the risk of typhoid compared to invasive non-typhoid Salmonella disease in Blantyre, Malawi. Sci. Rep. 9, 20310. DOI: $10.1038 / s 41598-019-56688-1$

Uzzau, S., Brown, D.J., Wallis, T., Rubino, S., Leori, G., Bernard, S., Casadesus. J., Platt, D.J., \& Olsen, J.E. (2000). Host adapted serotypes of Salmonella enterica. Epidemiol. Infect. 125(2), 229-255. DOI: $\underline{10.1017 / S 0950268899004379}$

Wales, A.D., Carrique - Mas, J.J., Rankin, M., Bell, B., Thind, B.B., \& Davies, R.H. (2010). Review of the carriage of zoonotic bacteria by arthropods, with special reference to Salmonella in mites, flies and litter beetles. Zoonoses. Publ. Health. 57, 299-314. DOI: 10.1111/j.1863-2378.2008.01222.x

WHO (World Health Organization) (2003). Salmonella (non-typhoidal). Fact sheets. Link

WHO (World Health Organization) (2017). Advancing the right to health: the vital role of law. Link

WHO (World Health Organization) (2020). Food Safety. Link.

Wierup, M., Engström, B., Engvall, A., \& Wahlström, H. (1995). Control of Salmonella Enteritidis in Sweden. Int. J. Food Microbiol. 25(2), 2019-226. DOI: 10.1016/0168-1605(94)00090-S

Winfield, M., \& Groisman, E. (2004). Evolution and Ecology of Salmonella. EcoSal. Plus. DOI: $\underline{10.1128 / e c o s a l .6 .4 .6}$

Xiaoxu, W., Yongmei, L., Sen, Z., Lifan, C., \& Bing, X. (2016). Impact of climate change on humaninfectious diseases: Empirical evidence and human adaptation. Environ. Int. 86, 14-23. DOI: 10.1016/j.envint.2015.09.007

Zhang, Y., Peng, B., \& Hiller, J. E. (2010). Climate variations and Salmonella infection in Australian subtropical and tropical regions. Sci. Total. Environ. 408, 524-530. DOI: 10.1016/j.scitotenv.2009.10.068 
Zinsstag, J, Schelling, E., Waltner-Toews, D., \& Tanner, M. (2011). From "One Medicine" to "One Health" and systemic approaches to health and well-being. Prev. Vet. Med. 101, 148-156. DOI: 10.1016/j.prevetmed.2010.07.003

Zinsstag, J, Schelling, E., Waltner-Toews, D., Whittaker, M., \& Tanner, M. (2015). One Health: The theory and practice of integrated health approaches, 1st ed. Wallingford, CAB International. DOI: $\underline{10.1079 / 9781780643410.0000}$

Zinsstag, J., Crump, L., Schelling, E., Hattendorf, J., Maidane, Y.O., Ali, K.O., Muhummed, A., Umer, A.A., Aliyi, F., Nooh, F., Abdikadir, M.I., Ali, S.M., Hartinger, S., Mäusezahl, D., de White, M.B.G., CordonRosales, C., Castillo, D.A., McCracken, J., Abakar, F., Cercamondi, C., Emmenegger, S., Maier, E., Karanja, S., Bolon, I., de Castañeda, R.R., Bonfoh, B., Tschopp, R., Probst-Hensch, N., \& Cissé, G. (2018). Climate change and One Health. FEMS Microbiol. Letters. 365, fny085. DOI: $\underline{10.1093 / \text { femsle/fny085 }}$

(C) Copyright 2020 by the authors. This is an open access article under the terms

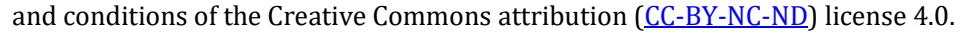

